\title{
Identification of Phytochemicals from the Water Extract of Eurycoma longifolia Roots using Solid-Liquid and Liquid-Liquid Extraction Based Fractionation Techniques
}

\author{
Lee Suan Chua, ${ }^{1,2, \star}$ Abirame Segaran ${ }^{1,2}$ and Hoi Jin Wong ${ }^{3}$ \\ ${ }^{1}$ Institute of Bioproduct Development, Universiti Teknologi Malaysia, 81310 UTM Skudai, Johor Bahru, Johor, Malaysia. \\ ${ }^{2}$ Department of Bioprocess and Polymer Engineering, School of Chemical and Energy Engineering, Faculty of Engineering, \\ Universiti Teknologi Malaysia, 81310 UTM Skudai, Johor Bahru, Johor, Malaysia. \\ ${ }^{3}$ Biotropics Malaysia Berhad, Lot 21, Jalan U1/19, Section U1, Hicom Glenmarie Industrial Park, 40150 Shah Alam, Selangor. \\ *Corresponding author: E-mail: lschua@ibd.utm.my; chualeesuan@utm.my \\ Tel.: +6019-7214378, fax: +607-5569706
}

Received: 05-29-2020

\begin{abstract}
Phytochemicals in the water extract of Eurycoma longofolia roots were identified using both solid-liquid and liquid-liquid extraction based fractionation techniques. A reversed phase C18 solid phase extraction (SPE) was used as solid-liquid extraction, whereas solvent partition was applied as liquid-liquid extraction. Total saponin was increased after fractionation. A few known quassinoids; eurycomanone, $13 \alpha(21)$-epoxyeurycomanone, pasakbumin D, 13 $\beta, 18$-dihydroeurycomanol and 13 $\beta, 21$-dihydroxyeurycomanol were identified from the $40 \%$ and $60 \%$ methanol fractions of SPE. Solvent partition extract using ethyl acetate was found to have the highest saponin content compared to butanol and chloroform fractions. Subsequent acetone precipitation of the organic fractions recovered a formylated hexose trimer and other saccharide-containing compounds. Ethyl acetate effectively recovered saponins from E. longofolia water extract using liquid-liquid extraction followed by acetone precipitation.
\end{abstract}

Keywords: Eurycomanone; Eurycoma longifolia; quassinoids; solid phase extraction; solvent partition; saponins

\section{Introduction}

Natural products are very complex in chemical composition. A wide range of phytochemicals with diverse properties tends to complicate the study of profiling. However, the demand of phytochemical profiling is getting increasingly necessary for plant authentication, identification and standardization. This is because the presence of phytochemicals will influence the quality of herbs, and subsequently affect the efficacy and safety of herbal products. Phytochemical profiling is an unbiased and comprehensive technique for quality control and standardization of herbal materials. Different high throughput and sensitivity techniques have been applied for phytochemical profiling. This includes LC-MS/MS, ${ }^{1}$ GC-MS, ${ }^{2}$ FTIR and 2DIR, ${ }^{3} \mathrm{NMR}^{4}{ }^{4} \mathrm{HPTLC}^{5}$ and so on with minimal sample preparation and treatment requirements.
Eurycoma longifolia Jack (Simaroubaceae) which is locally known as Tongkat Ali has been popularly called as Malaysian Ginseng. The roots of the herb are commonly prepared as ethnomedicine by indigenous people in the form of decoction to strengthen stamina and treat many diseases such as sexual dysfunction, malaria, cancer and androgen deficient osteoporosis. ${ }^{6-8}$ The application of the herbal decoction is still practiced till to date. Recent scientific findings have revealed that quassinoids are the major phytochemicals of E. longifolia. Quassinoids are the degraded triterpene lactones consisting of C-18, C-19, C-20, C-22, and C-25 types of compounds. ${ }^{9}$ Their derivatives usually present in the form of methylated, methoxylated, oxygenated, epoxylated and glycosylated quassinoids. In particular, triterpenoidal or steroidal saponins are abundant in the plant extract. Zaini et al. ${ }^{10}$ and Mutschlechner et al. ${ }^{11}$ developed and validated liquid chromatographic 
methods to identify quassinoids. In addition to quassinoids, there were also phenolics and alkaloids detected from the plant roots. ${ }^{12,13}$ Although total saponin has been estimated to be $>40 \%$ in the plant extract according to the Malaysian Standard, MS 2409:2011, ${ }^{14}$ the identification of individual saponins is relatively limited in literature. This could be due to the complexity of the chemical structure of saponins and the limitations of analytical instrumentation.

In the present study, fractionation technique was introduced in order to minimize the complexity of compounds in E. longifolia water extract. Both fractionation techniques; solid-liquid and liquid-liquid extractions were applied to separate the complex phytochemicals into few sub-clusters according to the polarity of solvents. Solid phase extraction (SPE) was applied as the solid-liquid extraction based fractionation technique using $\mathrm{C} 18$ reversed phase cartridge as absorbent. While, solvent partition was chosen as liquid-liquid extraction based fractionation technique. Three organic solvents; ethyl acetate, butanol and chloroform were chosen to partition phytochemicals. Previous studies reported that those solvents were suitable to partition saponins from ethanolic plant extracts, but were yet to be applied in SPE based fractionation. ${ }^{15}$ It is also known that saponins possess a wide range of polarity and solubility depending on the structural diversity of aglycone and sugar moieties. Often, saponins are reported to be abundant in plant roots rather than plant leaves and flowers. ${ }^{15,16}$ Therefore, it is also important to investigate phytochemicals in the water extract of $E$. longifolia roots since water extract is widely consumed in the form of decoction with ethnopharmacological importance.

\section{Experimental}

\section{1. Plant Material and Chemicals}

Physta $^{\circledR}$ (registration number, 2011000601) which is the proprietary standardized extract powder of Eurycoma longifolia roots was provided by Biotropics Malaysia Berhad (Shah Alam, Selangor, Malaysia). The plant extract was prepared at the stipulated temperature and pressure in water. Analytical grade of ethanol, ethyl acetate, chloroform, butanol, acetone and sulfuric acid (98\%) were purchased from Merck (Darmstadt, Germany). The LC grade of acetonitrile was sourced from Fisher Scientific (Chino, California, USA). Standard chemicals of vanillin ( $\geq 97 \%)$, escin $(\geq 95 \%)$ and oleanolic acid $(\geq 97 \%)$ were obtained from Sigma-Aldrich (St. Louis, MO, USA). C-18ec solid phase extraction (SPE) cartridges $(6 \mathrm{~mL}, 500 \mathrm{mg})$ were purchased from Macherey-Nagel (Duren, Germany).

\section{2. Solid-Liquid Extraction using C18ec SPE Cartridge}

Solid phase extraction was carried out to fractionate Physta into individual fractions using $\mathrm{C} 18 \mathrm{ec}$ cartridges.
The mobile phase was methanol at different concentrations ranged from $0-100 \% v / v$. The cartridges were activated using $100 \%$ methanol and followed by $100 \%$ water before use. Physta $(25 \mathrm{mg})$ was reconstituted in water $(0.5$ $\mathrm{mL}$ ) and loaded onto the cartridge. Elution was carried out and $3 \mathrm{~mL}$ was collected for each fraction.

\section{3. Solvent Partition by Liquid-Liquid Extraction}

Phytochemicals in Physta were also partitioned into different organic solvents such as ethyl acetate, butanol and chloroform using liquid-liquid extraction. Physta $(0.5 \mathrm{~g})$ was dissolved in water $(10 \mathrm{~mL})$ and extracted with $10 \mathrm{~mL}$ ethyl acetate vigorously in a $50 \mathrm{~mL}$ separating funnel. The top layer of organic phase was withdrawn and another fresh portion of ethyl acetate $(10 \mathrm{~mL})$ was added into the remaining aqueous phase for further extraction. The process was repeated for three times and the collected ethyl acetate fraction $(30 \mathrm{~mL})$ was combined for vacuum drying. Subsequently, the other two fractions, namely butanol and chloroform fractions were prepared using fresh Physta in separate experiments according to the above-mentioned procedures.

\section{4. Acetone Precipitation}

The organic fractions obtained from liquid-liquid extraction were reconstituted $(1 \mathrm{mg} / \mathrm{mL})$ in their respective solvents and slowly added into chilled acetone $(20 \mathrm{~mL})$ in dropwise manner. Precipitate was formed and harvested by centrifugation. The precipitate and the filtrate were then dried in an oven prior to LC-MS/MS analysis.

\section{5. Total Saponin Content}

The total saponin content was carried out according to the procedures described by Makkar et al. ${ }^{17}$ Samples were dissolved in $50 \%$ methanol and prepared by serial dilution. A $250 \mu \mathrm{L}$ sample $(1 \mathrm{mg} / \mathrm{mL})$ was mixed with $250 \mu \mathrm{L}$ vanillin $(8 \mathrm{~g} / 100 \mathrm{~mL}$ ethanol), and topped up with $2.5 \mathrm{~mL}$ sulfuric acid $(72 \%)$. The mixture was heated for $10 \mathrm{~min}$ at $60^{\circ} \mathrm{C}$, and then cooled in an ice-water bath for $5 \mathrm{~min}$. The absorbance of the mixture was recorded by a UV-vis spectrophotometer (UV-1800, Shimadzu, Japan) at $544 \mathrm{~nm}$. Escin and oleanolic acid were used as the standard chemicals for calibration. The results are expressed as milligram escin equivalent per milligram sample ( $\mathrm{mg} \mathrm{EE} / \mathrm{mg}$ ) or milligram oleanolic acid equivalent per milligram sample (mg OAE/mg).

\section{6. LC-PDA-MS/MS for Phytochemical Screening}

A hyphenated LC-MS/MS system was used to detect and identify compounds in samples. The system consisted of liquid chromatograph (Dionex Corporation Ultimate 
3000; Sunnyvale, CA) coupled to a diode array detector (Dionex Ultimate 3000) and a quadrupole - time-of-flight, QTOF mass spectrometer (AB SCIEX QSTAR Elite; Foster City, CA). All samples were prepared in $2 \mathrm{mg} / \mathrm{L}$ in the mixture of methanol and water (50:50) and then filtered through $0.2 \mu \mathrm{m}$ nylon membrane before injection into a C18 reversed phase XSelect HSS T3 column $(2.1 \times 100$ $\mathrm{mm}, 2.5 \mu \mathrm{m}$ ). The injection volume was $5 \mu \mathrm{L}$ and the detection was performed at the wavelength of $254 \mathrm{~nm}$. The mobile phase was composed of solvent A (water with $0.1 \%$ formic acid) and solvent $B$ (acetonitrile) and was programmed as: $0-10 \mathrm{~min}, 5 \% \mathrm{~B} ; 10-20 \mathrm{~min}, 5-90 \% \mathrm{~B} ; 20-25$ min, $90 \%$ B; $25-25.1 \mathrm{~min}, 90-5 \%$ B; $25.1-30 \mathrm{~min}, 5 \% \mathrm{~B}$. The flow rate of mobile phase was set at $0.15 \mathrm{~mL} / \mathrm{min}$.

The mass range of $m / z 120-2000$ was set for mass spectrometer in phytochemical screening. The TOF MS scan was acquired with two dependent product ion scans using rolling collision energy. Nitrogen gas was used as nebulizing (40 psi) and curtain (20 psi) gas. The voltage of ion spray was set at $-4500 \mathrm{~V}$ and $5500 \mathrm{~V}$ for negative and positive ion modes, respectively. The declustering potential and the focusing potential was set at $40 \mathrm{~V}$ and $300 \mathrm{~V}$, respectively.

\section{Results and Discussion}

\section{1. Phytochemical Ccreening of Eurycoma longifolia Extract}

Physta which is consisted of a complex mixture of phytochemicals was extracted from the raw material of $E$. longifolia roots. A fast screening process for phytochemicals in Physta was carried out using LC-PDA-MS/MS. The detected compounds based on their fragment ions are listed in Suppl. Mat. Table S1 for both positive and negative ion modes. The results revealed that they were mostly from the group of quassinoids which are also known as degraded triterpenes with all-chair cyclic and highly oxygenated squalene. This also explains the bitter principle of the plant extract.

\section{2. Solid Phase Extraction Based Fractionation}

The principle of solid-liquid extraction was used to separate phytochemicals in Physta into individual fractions using aqueous methanol as the mobile phase and C18ec cartridge as the adsorbent. The total saponins of fractions are presented in Figure 1. The 40\% methanol fraction shows to have the highest total saponins. The results expressed in escin equivalent were about 2 times higher than those results expressed in oleanolic acid equivalent. Escin is a saponin with larger molecular size $(1131.269 \mathrm{~g} / \mathrm{mol})$ compared to oleanolic acid $(456.711 \mathrm{~g} /$ $\mathrm{mol}$ ). The presence of 3 sugar moieties in the molecular structure of escin may hinder its hydroxyl group at C-3 and double bond at $\mathrm{C}-12$ to react with vanillin in order to form a red coloured complex for measurement. The hindrance can be seen from the lower slope of calibration curve exhibited by escin, and therefore higher total saponins expressed in escin equivalent.

The chromatogram shows an intense peak at 12.5 min for the $40 \%$ methanol fraction (Figure 2). The chromatogram of $100 \%$ methanol fraction shows no peak, but

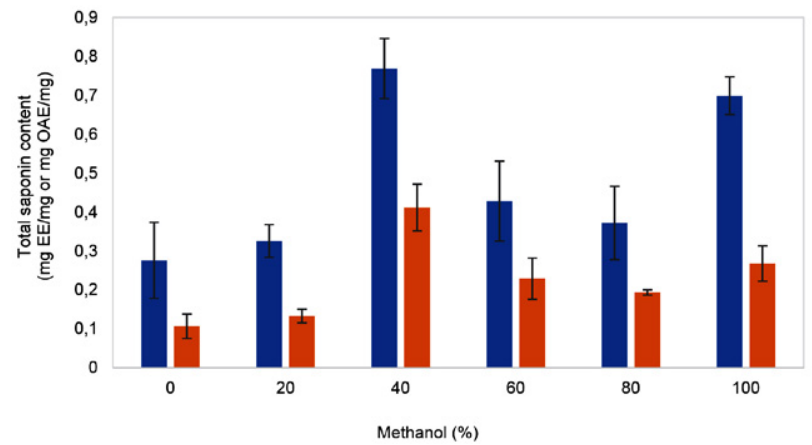

Figure 1. Total saponin content of Eurycoma longifolia fractions collected from solid phase extraction where blue bars are total saponin content expressed in milligram escin equivalent per milligram sample (mg EE/mg) and orange bars are total saponin content expressed in milligram oleanolic acid equivalent per milligram sample (mg OAE/mg).

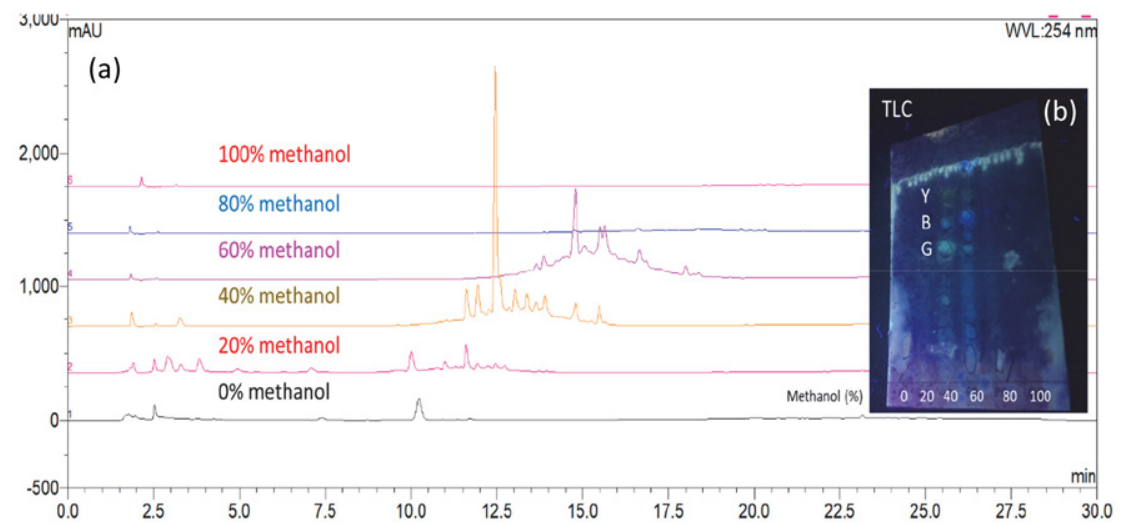

Figure 2. Chromatograms of methanol fractions collected from the elution of Eurycoma longifolia water extract using C18ec cartridges. The compound detection was performed using (a) liquid chromatography and (b) thin layer chromatography. 
its total saponin content was the second highest among the fractions. Saponins in that fraction could have non-UV-absorbing property for detection. The $40 \%$ methanol fraction was also spotted on thin layer chromatographic plate. Interestingly, the plate displayed 3 intense spots with the retention factors of 0.62 (green), 0.74 (blue) and 0.88 (yellow) on the plate eluted by the solvent system consisting of chloroform: methanol: water (32:8:1). Saponins usually produce yellowish up to blue or violet blue spots after spraying with vanillin-sulfuric acid reagent and heating until dryness prior to visualization under UV light at $254 \mathrm{~nm} .{ }^{18}$ The colour was attributed to the formation of complex compound from the reaction of vanillin with tri- terpenoidal or steroidal aglycone in the presence of sulfuric acid as a strong oxidizing agent. ${ }^{19}$

The $40 \%$ methanol fraction was further purified using another new $\mathrm{C} 18 \mathrm{ec}$ SPE cartridge into a few sub-fractions. The gradient of methanol was slowly increased from $5,7,10,15$, and $20 \%$ and $3 \mathrm{~mL}$ was also collected for each fraction. It was found that peak 3 could be retained longer in the cartridge for better separation from peak 1 and 2 (Figure 3 ). The peaks were tentatively identified as eurycomanone (peak 3 ) and its derivatives (peak 1 and 2) as presented in Table 1. This is also the first report to isolate eurycomanone using SPE assisted by analytical techniques of thin layer chromatography and LC-PDA-MS/MS. Euryco-

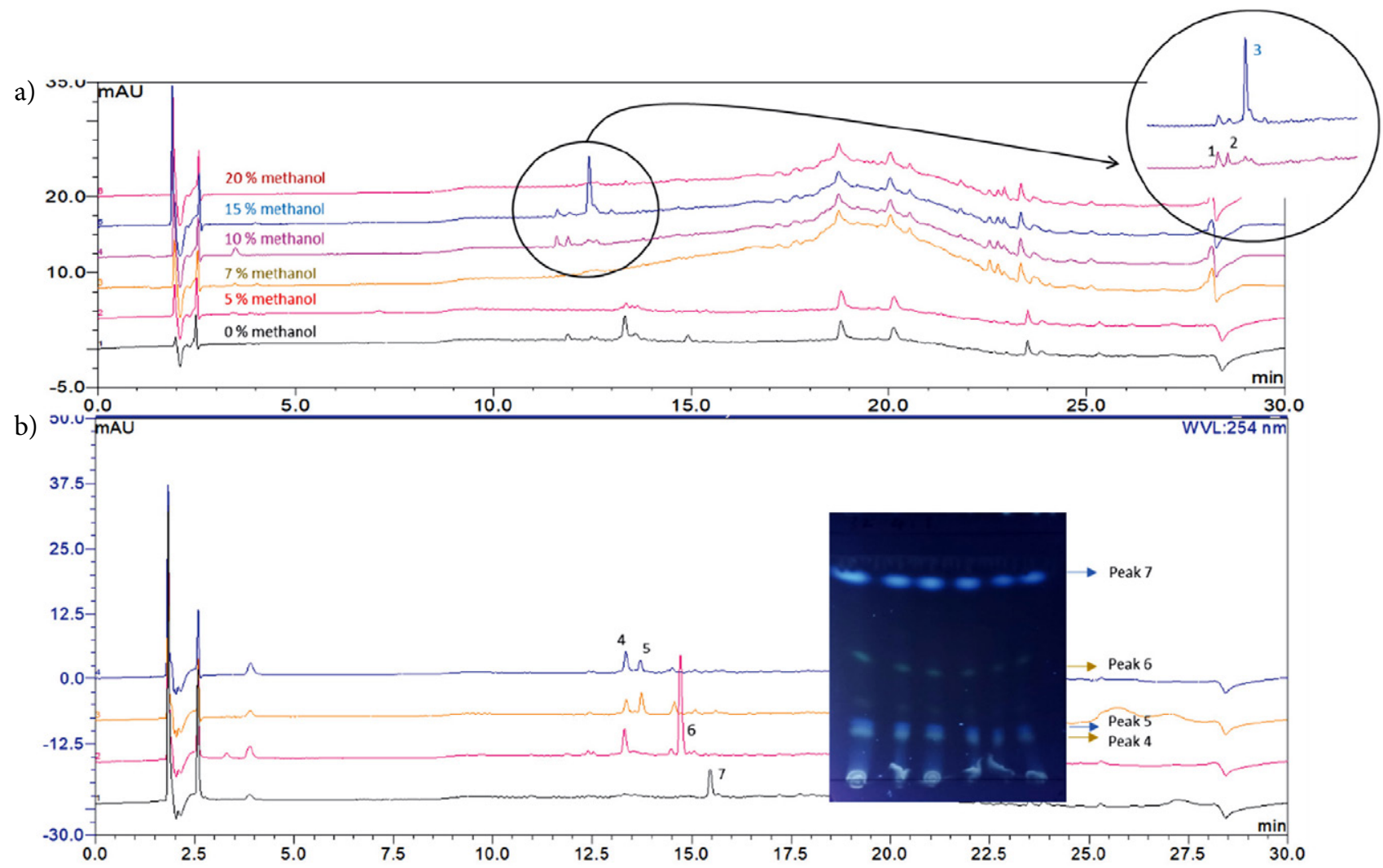

Figure 3. (a) Chromatograms of sub-fractions collected from the $40 \%$ methanol fraction using C18ec cartridge in solid phase extraction, (b) chromatograms of 4 intense spots collected from thin layer chromatographic plate using $60 \%$ methanol fraction.

Table 1. Putative compounds detected from $40 \%$ and $60 \%$ methanol fractions spotted on the plates of thin layer chromatography.

\begin{tabular}{|c|c|c|c|c|c|c|}
\hline Peak & $\begin{array}{l}\text { Retention } \\
\text { time (min) }\end{array}$ & $\begin{array}{l}\text { Retention } \\
\text { factor }\end{array}$ & Positive ion $(\mathrm{m} / \mathrm{z})$ & Negative ion $(m / z)$ & $\begin{array}{l}\text { Putative compound } \\
\text { on TLC plate }\end{array}$ & $\begin{array}{l}\text { Spot } \\
\text { colour }\end{array}$ \\
\hline 1 & 11.3 & 0.88 & $443 / 425 / 407 / 389 / 359 / 267$ & $441 / 331 / 301 / 285$ & Pasakbumin D & Yellow \\
\hline 2 & 11.6 & 0.74 & $425 / 407 / 397 / 389 / 377 / 361 / 343 / 267$ & $423 / 301$ & $\begin{array}{c}13 \alpha(21) \text {-epoxyeurycomanone } \\
\text { (Pasakbumin B) }\end{array}$ & Blue \\
\hline 3 & 12.5 & 0.62 & $409 / 391 / 373$ & $407 / 299 / 287$ & Eurycomanone (Pasakbumin A) & Green \\
\hline 4 & 13.5 & 0.47 & $413 / 395 / 377 / 359 / 285$ & $411 / 291$ & $13 \beta, 18$-dihydroeurycomanol & yellow \\
\hline 5 & 13.7 & 0.50 & $445 / 429 / 415 / 405 / 397 / 343$ & $443 / 379 / 317$ & $13 \beta, 21$-dihydroxyeurycomanol & Blue \\
\hline 6 & 14.7 & 0.67 & na & $441 / 395 / 377$ & unknown & Yellow \\
\hline 7 & 15.4 & 0.97 & $193 / 178$ & $191 / 176$ & Scopoletin ${ }^{\star}$ & Violet blue \\
\hline
\end{tabular}

${ }^{\star}$ Refer to reference [5] and https://massbank.eu/MassBank/Search (BML00378) 
manone belongs to the $\mathrm{C} 20$ quassinoid which is well known as the biomarker of E. longifolia with pharmacological activities such as enhancing testosterone steroidogenesis, ${ }^{20}$ antimalarial activity against Plasmodium falciparum William H. Welch (Plasmodiidae) strains, ${ }^{21}$ suppressing the expression of lung cancer cell tumour markers ${ }^{22}$ and regulating signaling pathways of cell proliferation, cell death and inflammation..$^{23}$

The second dimension of SPE did not improve the separation of peaks in $60 \%$ methanol fraction. Hence, $60 \%$ methanol was also spotted on the TLC plate and observed under UV light at $254 \mathrm{~nm}$. There were 4 intense spots with the retention factors of 0.47 (yellow), 0.5 (blue), 0.67 (yellow) and 0.97 (violet blue) using the solvent system of chloroform:methanol:water (32:4:1). Four intense spots were scratched from the TLC plate, collected in tubes and extracted with methanol. The methanol solution was filtered and injected for LC-PDA-MS/MS analysis. The chromatograms of the four intense spots are presented in Figure 3 and their putative compounds (peak 4-7) are also tabulated in Table 1. Scopoletin (peak 7) is a plant growth regulator which is also a derivative of coumarin.

\section{3. Solvent Partition of Eurycoma longifolia Extract}

In another fractionation technique, E. longifolia extract was reconstituted in water and partitioned using different organic solvents, namely ethyl acetate, butanol and chloroform. The results showed that ethyl acetate could recover a wide range of phytochemicals with the retention time ranged from $12-19$ min, especially peak 7 and 8 as presented in Figure 4. The phytochemicals were mostly partitioned in ethyl acetate because of high dipole moment (1.78) of the solvent. However, butanol was likely to extract more polar phytochemicals such as peak 1 and 2 . On the other hand, chloroform preferred to partition less polar phytochemicals (peak 7 and 8). The chromatographic profile of chloroform fraction was close to the profile of ethyl acetate fraction. Chloroform and ethyl acetate could recover peak 7 significantly compared to peak 2 which could be recovered more by butanol. Peak 8 was another intense peak recovered by ethyl acetate. The putative compounds of the assigned peaks are listed in Suppl. Mat. Table S1. In line with the chromatograms (Figure 4), total saponin content of ethyl acetate fraction was found to be the highest in escin or oleanolic acid equivalent per milligram sample (Table 2). The results showed to have similar descending trend of total saponins in the fractions of ethyl acetate, chloroform and butanol partitioned from ethanolic extract in previous studies. ${ }^{15}$ The total saponin in butanol fraction was lower than chloroform fraction. However, butanol fraction showed to have a significant increment of saponins after acetone precipitation. Another observation was that total saponins of the organic fractions were inversely related to their recovered amount. Although butanol fraction had the lowest total saponins, the fraction was shown to have the highest weight (17\%). The weight of chloroform and ethyl acetate fractions was $9.3 \%$ and $4.7 \%$, respectively. This indicates that other compounds rather than saponins could be partitioned in butanol.

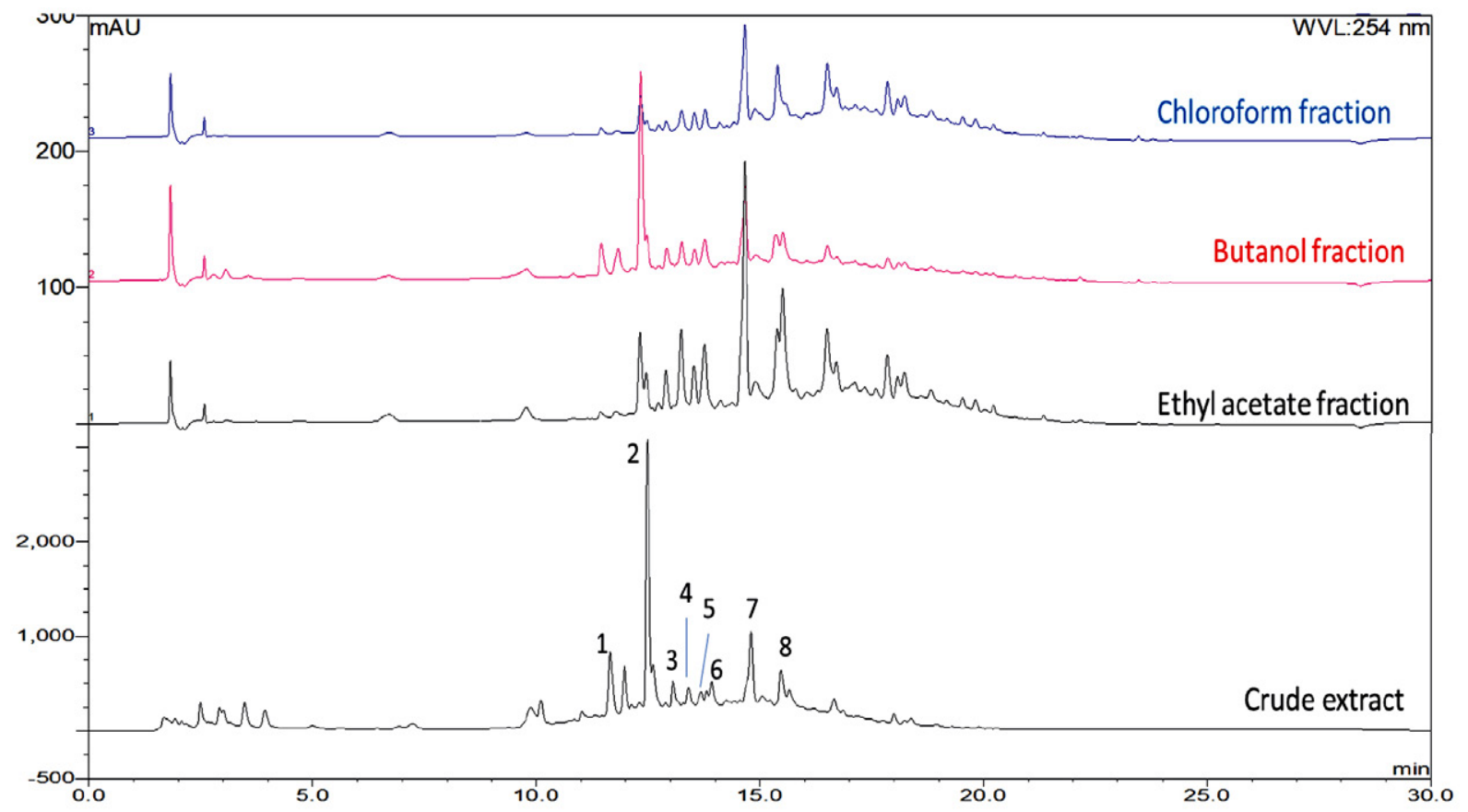

Figure 4. Chromatograms of Eurycoma longifolia extract and its organic fractions; ethyl acetate, butanol and chloroform. Peak 1-8 have been assigned in Suppl. Mat. Table S1. 
Table 2. Total saponin content of organic fractions and their aqueous counterparts after solvent partition, and precipitates and its filtrates after acetone precipitation

\begin{tabular}{llcc}
\hline & \multicolumn{3}{c}{ Total saponin content of solvent partition } \\
& Sample & mg EE/mg & mg OAE/mg \\
\hline \multirow{3}{*}{ Organic } & Extract & $0.10 \pm 0.03$ & $0.05 \pm 0.02$ \\
fraction & Ethyl acetate & $0.68 \pm 0.03$ & $0.34 \pm 0.01$ \\
& Butanol & $0.36 \pm 0.05$ & $0.19 \pm 0.01$ \\
Aqueous & Chloroform & $0.53 \pm 0.03$ & $0.23 \pm 0.02$ \\
fraction & Ethyl acetate & $0.22 \pm 0.05$ & $0.09 \pm 0.02$ \\
& Butanol & $0.28 \pm 0.04$ & $0.07 \pm 0.02$ \\
& Chloroform & $0.33 \pm 0.02$ & $0.13 \pm 0.02$ \\
\hline \multirow{4}{*}{ Precipitate } & Total saponin content of acetone precipitate \\
& Sample & mg EE/mg & mg OAE/mg \\
\hline & Extract & $0.29 \pm 0.08$ & $0.04 \pm 0.01$ \\
& Chylanol & $0.62 \pm 0.18$ & $0.83 \pm 0.15$ \\
& Chloroform & $0.52 \pm 0.17$ & $0.22 \pm 0.06$ \\
& Extract & $0.59 \pm 0.19$ & $0.27 \pm 0.11$ \\
Filtrate & Ethyl acetate & $1.09 \pm 0.21$ & $0.66 \pm 0.13$ \\
& Butanol & $0.64 \pm 0.16$ & $0.32 \pm 0.03$ \\
& Chloroform & $0.98 \pm 0.20$ & $0.58 \pm 0.07$ \\
\hline
\end{tabular}

$\mathrm{mg} \mathrm{EE} / \mathrm{mg}$ denotes milligram escin equivalent per milligram sample $\mathrm{mg} \mathrm{OAE} / \mathrm{mg}$ denotes oleanolic acid equivalent per milligram sample

Subsequently, the organic fractions were slowly precipitated in cold acetone. The results found that acetone precipitation improved the total saponin content of precipitates (Table 2). In particular, the precipitate of ethyl acetate fraction showed to have an increment in total saponins from its fraction. The fraction also shows to have slightly higher total saponins than its filtrate as shown in Table 2. The observation explains that saponins in E. longifolia are favourable to stay in ethyl acetate than acetone. The solvation of saponins was limited and precipitate was rapidly formed when ethyl acetate fraction was slowly dropped into the large volume of cold acetone. Therefore, saponins in E. longifolia could be recovered by ethyl acetate $>$ butanol $>$ chloroform in descending order. Again, total saponins recovered from the precipitation method were not in line with the harvested amount of precipitates.
Chloroform precipitate achieved the highest amount, $47 \%$, followed by ethyl acetate precipitate (12\%) and butanol precipitate $(8 \%)$.

Direct precipitation of $E$. longifolia extract in cold acetone without the process of solvent partition produced a sticky precipitate. This sticky precipitate is believed to be mostly polysaccharides. Polysaccharides are soluble in water and they immediately formed a precipitate in acetone. The attractive hydrogen bonding forces within the polysaccharide chain become more prevalent in acetone. Their polysaccharide chains tend to bond within and between themselves rather than with the solvent. These intra- and intermolecular hydrogen bonds lead to agglomeration and precipitation as solvation decreases. This approach appeared to be effective to recover polysaccharides. Approximately half of the E. longifolia extract could be precipitated in cold acetone (51\%).

The chromatograms of organic fractions and their precipitates are illustrated in Suppl. Mat. Figure S1. Almost no peak could be detected in the precipitates by UV detector of liquid chromatography. The compounds in precipitates could have non-UV-absorbing property. The total ion chromatogram (TIC) of mass analyzer shows to have an intense peak for the precipitates. The intense peak was found to have $m / z 723 / 677(-46) / 593 / 451(-226) / 431$ and $\mathrm{m} / \mathrm{z} 792 / 679 / 661 / 565 / 548 / 453 / 435 / 341 / 228 / 116$ for negative and positive ion modes, respectively. The presence of $\mathrm{m} / \mathrm{z} 723$ was also detected in previous studies of similar group of researchers. ${ }^{15}$ The compound was tentatively identified as $[3 \mathrm{M}+\mathrm{HCOOH}]$, namely 3 monomers of formylated hexoses with formate adduct ion. The other detected saccharide-containing compounds are tabulated in Table 3. The detection was performed at the negative ion mode as previous studies reported that saccharide-containing compounds were more ionizable in the negative ion mode. ${ }^{10}$ The result showed to have more saccharide-containing compounds detected from the chloroform precipitate in this study. Although many studies had been conducted for E. longifolia roots, most of the studies were focused on the quassinoids and biological properties of the plant crude extract. There were limited studies on the application of fractionation techniques to recover saponins

Table 3. Detected saccharide-containing compounds from the precipitates of organic fractions

\begin{tabular}{llccc}
\hline $\boldsymbol{t}_{\mathrm{R}}(\boldsymbol{m i n})$ & Negative ion $(\boldsymbol{m} / \boldsymbol{z})$ & Ethyl acetate & $\begin{array}{c}\text { Precipitates } \\
\text { Butanol }\end{array}$ & Chloroform \\
\hline 12.5 & $407 / 299(-108) / 287(-120) / 283 / 271(-136)$ & & $\sqrt{ }$ \\
12.6 & $575(-46) / 529 / 395 / 367(-162) / 349 / 331$ & $\sqrt{ }$ & $\sqrt{ }$ \\
13.5 & $557 / 349(-208) / 313$ & & $\sqrt{ }$ \\
14.0 & $695 / 449(-246) / 253(-196)$ & $\sqrt{ }$ & $\sqrt{ }$ \\
15.0 & $587 / 541(-46) / 407 / 343 / 333(-162) / 179$ & $\sqrt{ }$ & $\sqrt{ }$ \\
15.5 & $723 / 677(-46) / 593 / 451(-226) / 387 / 341 / 225 / 179$ & $\sqrt{ }$ & $\sqrt{ }$ \\
17.4 & $819 / 657(-162) / 476$ & & $\sqrt{ }$ \\
19.8 & $401 / 357 / 313 / 225(-176) / 181 / 121$ & & $\sqrt{ }$ \\
\hline
\end{tabular}


from E. longifolia. Elhag et al. ${ }^{24}$ applied the sequential extraction just to optimize the yield of saponins using ultrasound assisted extraction followed by water extraction. However, this study applied solvent partition to increase saponin content, and consequently identify mass fragmentation patterns of saccharide-containing compounds which could be saponins in the organic fractions.

\section{Conclusions}

The phytochemical profile of E. longifolia extract had been investigated using the fractionation techniques of solid-liquid and liquid-liquid extraction. Both techniques could increase total saponin content of samples. The technique of solid-liquid extraction was found to identify few previously reported quassinoids including the marker compound, eurycomanone in the $40 \%$ methanol fraction. While the technique of liquid-liquid extraction followed by acetone precipitation could increase the total saponin content of ethyl acetate fraction. Precipitates of chloroform fractions did not show significant increment of saponin content. Nevertheless, formylated hexose trimer was found to be the most significant saccharide-containing compound in the precipitates. The detection of $\mathrm{m} / \mathrm{z}$ and their fragment ions could be further studied to elucidate the structural diversity of saponins in E. longifolia roots.

\section{Acknowledgement}

The authors would like to thank the internship students; Ms Lee Yik Sin (Universiti Malaysia Kelantan), Ms. Nor Hanani Ab Halim (Universiti Malaysia Terengganu) and Ms. Norfarahin Hamzah (Universiti Malaysia Pahang) for their efforts to prepare samples for experiments. High appreciation is also given to Ministry of Higher Education, Malaysia (HICoE 4J263) and Biotropics Malaysia Berhad (4C177) for giving research grants.

\section{References}

1. L. S. Chua, N. A. Amin, J. C. Neo, T. H. Lee, C. T. Lee, M. R. Sarmidi, R. A. Aziz, J. Chromatogr. B Analyt. Technol. Biomed. Life Sci. 2011, 879, 3909-3919.

DOI:10.1016/j.jchromb.2011.11.002

2. A. K. M. S. Islam, Z. Ismail, B. Saad, A. R. Othman, M. N. Ahmad, A.Y.M. Shakaf, Sensor Actuators B: Chem. 2006, 120, 245-251. DOI:10.1016/j.snb.2006.02.020

3. A. M. Adib, Z. Abdullah, Vib. Spectrosc. 2018, 96, 1-9. DOI:10.1016/j.vibspec.2018.02.003

4. F. Ebrahimi, B. Ibrahim, C. H. Teh, V. Murugaiyah, C. K. Lam, Planta Med. 2017, 83, 172-182.

DOI:10.1055/s-0042-110857
5. N. Zakaria, K. S. Mohd, M. S. R. Hamil, A. H. Memon, A. Z. Asmawi, Z. Ismail, J. Fundam. Appl. Sci. 2017, 9, 661-679.

DOI:10.4314/jfas.v9i2s.41

6. M. Tambi, A. Kadir, Asian J. Androl. 2006, 8, 49-50.

7. P. C. Kuo, A. G. Damu, K. H. Lee, T. S. Wu, Biorg. Med. Chem. 2004, 12, 537-544. DOI:10.1016/j.bmc.2003.11.017

8. G. Fiaschetti, M. Grotzer, T. Shalaby, D. Castelletti, A. Arcaro, Curr. Med. Chem. 2010, 18, 316-328.

DOI:10.2174/092986711794839205

9. S. Park, N. X. Nhiem, P. V. Kiem, C. V. Minh, B. H. Tai, N. Kim, H. H. Yoo, J. H. Song, H. J. Ko, S. H. Kim, Bioorg. Med. Chem. Lett. 2014, 24, 3835-3840.

DOI:10.1016/j.bmcl.2014.06.058

10. N. N. Zaini, O. Rozita, J. Hafizan, S. Norashikin, Molecules, 2016, 21, 583. DOI:10.3390/molecules 21050583

11. B. Mutschlechner, S. Schwaiger, T. V. A. Tran, H. Stuppner, Fitoterapia, 2018, 124, 188-192.

DOI:10.1016/j.fitote.2017.11.015

12. P. B. Ngoc, T. B. Pham, H. D. Nguyen, T. T. Tran, H. H. Chu, V. M. Chau, J. H. Lee, T. D. Nguyen, Nat. Prod Res. 2016, 30, 1360-1365. DOI:10.1080/14786419.2015.1056187

13. J. Ruan, Z. Li, Y. Zhang, Y. Chen, M. Liu, L. Han, Y. Zhang, T. Wang, Molecules, 2019, 24, 3157.

DOI:10.3390/molecules24173157

14. Malaysian Standard, MS 2409, Department of Standards Malaysia: Cyberjaya, SGR, Malaysia, 2011.

15. L. S. Chua, C. H. Lau, C. Y. Chew, D.A.S. Dawood, Molecules 2019, 24, 1416. DOI:10.3390/molecules 24071416

16. N. Husain, A. Kumar, Int. J. Sci. Res. 2016, 5, 1613-1615.

17. H. P. S. Makkar, P. Siddhuraju, K. Becker, in: Methods in Molecular Biology 393. New Jersey, Humana Press, Clifton, 2007, p. 93-100. DOI:10.1007/978-1-59745-425-4_16

18. W. Oleszek, I. Kapusta, A. Stochmal, in: Waksmundzka-Hajnos M, Sherma J, Kowalska T (Eds): Thin Layer Chromatography in Phytochemistry. 1st ed. New York, CRC Press, Taylor \& Francis Group, 2008, p. 519-41.

19. A. V. Le, S. E. Parks, M. H. Nguyen, P. D. Roach, Technologies 2018, 6, 84. DOI:10.3390/technologies6030084

20. B. S. Low, S. B. Choi, H. Abdul Wahab, P. K. Das, K. L. Chan, J. Ethnopharmacol. 2013, 149, 201-207.

DOI:10.1016/j.jep.2013.06.023

21. K. L. Chan, C. Y. Choo, N. R. Abdullah, Z. Ismail, J. Ethnopharmacol. 2014, 92, 223-227.

DOI:10.1016/j.jep.2004.02.025

22. P. F. Wong, W.F. Cheong, M. H. Shu, C. H. Teh, K. L. Chan, S. Abu Bakar, Phytomed. 2012, 19, 138-144.

DOI:10.1016/j.phymed.2011.07.001

23. S. Hajjouli, S. Chateauvieux, M. H. Teiten, B. Orlikova, M. Schumacher, M. Dicato, C.Y. Choo, M. Diederich, Molecules 2014, 19, 14649-66. DOI:10.3390/molecules190914649

24. H. E. E. A. Elhag, A. Naila, A. Ajit, B. A. Aziz, A. Z. Sulaiman, Materials Today: Proceedings, 2018, 5, 21672-21681. DOI:10.1016/j.matpr.2018.07.018 


\section{Povzetek}

V vodnem ekstraktu korenin rastline Eurycoma longofolia smo identificirali fitokemikalije s tehnikami frakcionacije trdno-tekoče in tekoče-tekoče. Kot ekstrakcijo trdno-tekoče smo uporabili reverzno-fazno C18 ekstrakcijo na trdno fazo (SPE), medtem ko smo kot ekstrakcijo tekoče-tekoče uporabili porazdeljevanje med topila. Po frakcionaciji se je povečala vsebnost skupnih saponinov. V $40 \%$ in $60 \%$ metanolni frakciji SPE smo identificirali nekaj poznanih kasinoidov: eurikomanon, $13 \alpha(21)$-epoksieurikomanon, pasakbumin D, 13 $\beta, 18$-dihidroeurikomanol in 13 $\beta$,21-dihidroksieurikomanol. Ugotovili smo, da ima največjo vsebnost saponinov ekstrakt po porazdeljevanju v etil acetat, v primerjavi $\mathrm{z}$ butanolno in kloroformno frakcijo. $\mathrm{Z}$ nadaljnjim obarjanjem organskih frakcij $\mathrm{z}$ acetonom smo pridobili formilirani heksozni trimer in druge saharide vsebujoče spojine. Z ekstrakcijo tekoče-tekoče z etil acetatom, ki ji je sledilo obarjanje $\mathrm{z}$ acetonom, smo učinkovito izolirali saponine iz vodnega ekstrakta rastline E. longofolia. 